\title{
Parts of speech: Solid citizens or slippery customers?
}

DOI:

$10.5871 / \mathrm{jba} / 001.151$

Document Version

Final published version

Link to publication record in Manchester Research Explorer

\section{Citation for published version (APA):}

Denison, D. (2013). Parts of speech: Solid citizens or slippery customers? Journal of the British Academy, 1, 151185. https://doi.org/10.5871/jba/001.151

\section{Published in:}

Journal of the British Academy

\section{Citing this paper}

Please note that where the full-text provided on Manchester Research Explorer is the Author Accepted Manuscript or Proof version this may differ from the final Published version. If citing, it is advised that you check and use the publisher's definitive version.

\section{General rights}

Copyright and moral rights for the publications made accessible in the Research Explorer are retained by the authors and/or other copyright owners and it is a condition of accessing publications that users recognise and abide by the legal requirements associated with these rights.

\section{Takedown policy}

If you believe that this document breaches copyright please refer to the University of Manchester's Takedown Procedures [http://man.ac.uk/04Y6Bo] or contact uml.scholarlycommunications@manchester.ac.uk providing relevant details, so we can investigate your claim.

\section{open 2 Access}




\title{
Parts of speech: Solid citizens or slippery customers?
}

\author{
Joint British Academy/Philological Society Lecture \\ read 10 May 2013 by
}

\section{DAVID DENISON}

Abstract: The 'parts of speech' which have played a fundamental role in most descriptions of grammar, from primary school curriculum to advanced linguistic theory, are explored in this article, which considers some intriguing changes in recent everyday English that challenge traditional assumptions about the definition and usefulness of word classes such as 'pronoun', 'adjective' and 'noun'. The article raises important questions about what happens at the boundaries between these word classes and looks at how we can answer these questions-potentially changing the direction of both future linguistic research and pedagogical practice.

Key words: part of speech, category, underspecification, gradience, vagueness, dual inheritance, grammar in schools

\section{INTRODUCTION}

This paper is based on a lecture proposed in a joint invitation by the Philological Society and the British Academy. ${ }^{1}$ I am grateful for the invitation, which can be taken as a nice illustration of dual inheritance, in that my talk was supposed to inherit the typical properties of both a Philological Society research presentation and a British Academy public lecture. Dual inheritance is a technical term, which I will return to briefly later on. ${ }^{2}$

Linguistics makes use of all sorts of units, categories, relationships and technical terms. In this population of linguistic participants, how useful and how reliable are

${ }^{1}$ I owe thanks to Tine Breban, Dick Hudson, Marianne Hundt, Paul Kiparsky, Eva Schultze-Berndt and Benedikt Szmrecsanyi for commenting on draft versions of the lecture and/or paper, and to Hendrik De Smet and John Payne for helpful discussions of individual points. They are not to be blamed for what remains.

${ }^{2}$ If the inheritances are incompatible, the resulting stalemate is a so-called 'Nixon diamond' (Hudson 2000). 
the Parts of Speech (abbreviated PoS)? That is my topic. The paper is organised as follows. I ask how we recognise PoS, then look at items which change their PoS, then discuss the theoretical consequences. After that I turn to grammar in schools, before a conclusion which attempts to answer the question of my title.

\section{PART 1: THE WHERE AND WHAT OF POS}

The existence of a fixed set of word classes is axiomatically given in most linguistic theories: Minimalism, Lexical-Functional Grammar (LFG), Head-Driven Phrase Structure Grammar (HPSG), Word Grammar, and others. ${ }^{3}$ It is unsurprising that generalisation across words is found useful for writing an economical grammar of a language which according to the Oxford English Dictionary (henceforth OED) has over 600,000 words, and so word classes of some kind are often employed. I will use the terms part of speech and word class interchangeably, though some authors distinguish them. Words are marked for PoS in almost all dictionaries, monolingual and bilingual. PoS are widely used in foreign language teaching in schools. They have been used in schools for the teaching of English language-apart from an interruption from the 1960s to 1999 or so (Hudson \& Walmsley 2005). Surely a concept in such wide and varied use must be both useful and workable? Parts of speech capture patterns, generalisations. For a linguist, this represents an economy of description, which is obviously desirable. But what is the generalisation captured by PoS? We should have an answer by the end of the paper.

I start with an example. Do we know the PoS in (1)?

(1) A splendid Phil Soc tea can make you sleepy.

Probably everyone instantly identifies splendid and sleepy as adjectives (Adj), make as a verb (V), and the noun (N) tea. (Perhaps you are happy to assign PoS labels to every word in (1), though at best there is likely to be some disagreement about the minor classes. Linguists disagree too: see below in the section 'A professional view: The Cambridge Grammar'.) So we have at least:

(1)' A splendid Phil Soc tea $_{\mathrm{N}}$ can make $_{\mathrm{V}}$ you sleepy $_{\mathrm{A}}$

But how do we do it? I can no longer recall how I learnt the PoS at school. I expect some years of French, Latin and then German will have been at least as helpful as anything we did in English lessons, but you shouldn't need to learn or use another language to be able to discuss your own.

${ }^{3}$ Perhaps not in Role and Reference Grammar (RRG) (Delia Bentley, pers. comm. 8 July 2013). 


\section{What they mean: notional definition}

We often think we identify PoS on the basis of meaning — so-called notional definitions like

$$
\begin{aligned}
& \mathrm{N}=\text { name of a person, place or thing } \\
& \mathrm{Adj}=\text { a describing word } \\
& \mathrm{V}=\text { a doing word }
\end{aligned}
$$

Suppose you didn't know that tea in (1) is a noun, could you look at its meaning? Why not?

A noun is often defined as the name given to a person, place or thing. Typically, these are physical entities that can be seen, touched, smelt, tasted or heard. (From a 2013 Glossary of Terms for National Curriculum Assessments, possibly now superseded; http://media.education.gov.uk/assets/files/pdf/g/2013\%20ks2_egps_glossaryofterms. pdf)

Tea is a thing, or a collection of things, bounded in space, so it's a noun.

But wait. The same source gives the following definition:

A verb is a word that [ . . ] expresses an action, an event, a process, a sensation or a state of being (ibid.)

The tea before my lecture was an event, bounded in time: $3.45-4.15$, I was firmly told.

So it's a verb? Admittedly, I omitted the part of the definition of verbs that mentioned the possibility of tense inflection, but two obvious rejoinders spring to mind. First, at this point we're trying to define PoS by meaning, and second, the word tea can (if marginally) take a tense inflection:

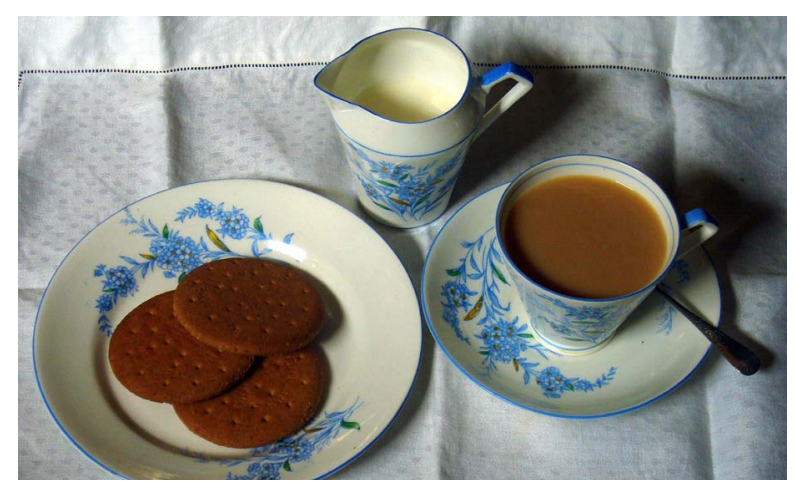

Figure 1. Tea and biscuits. 


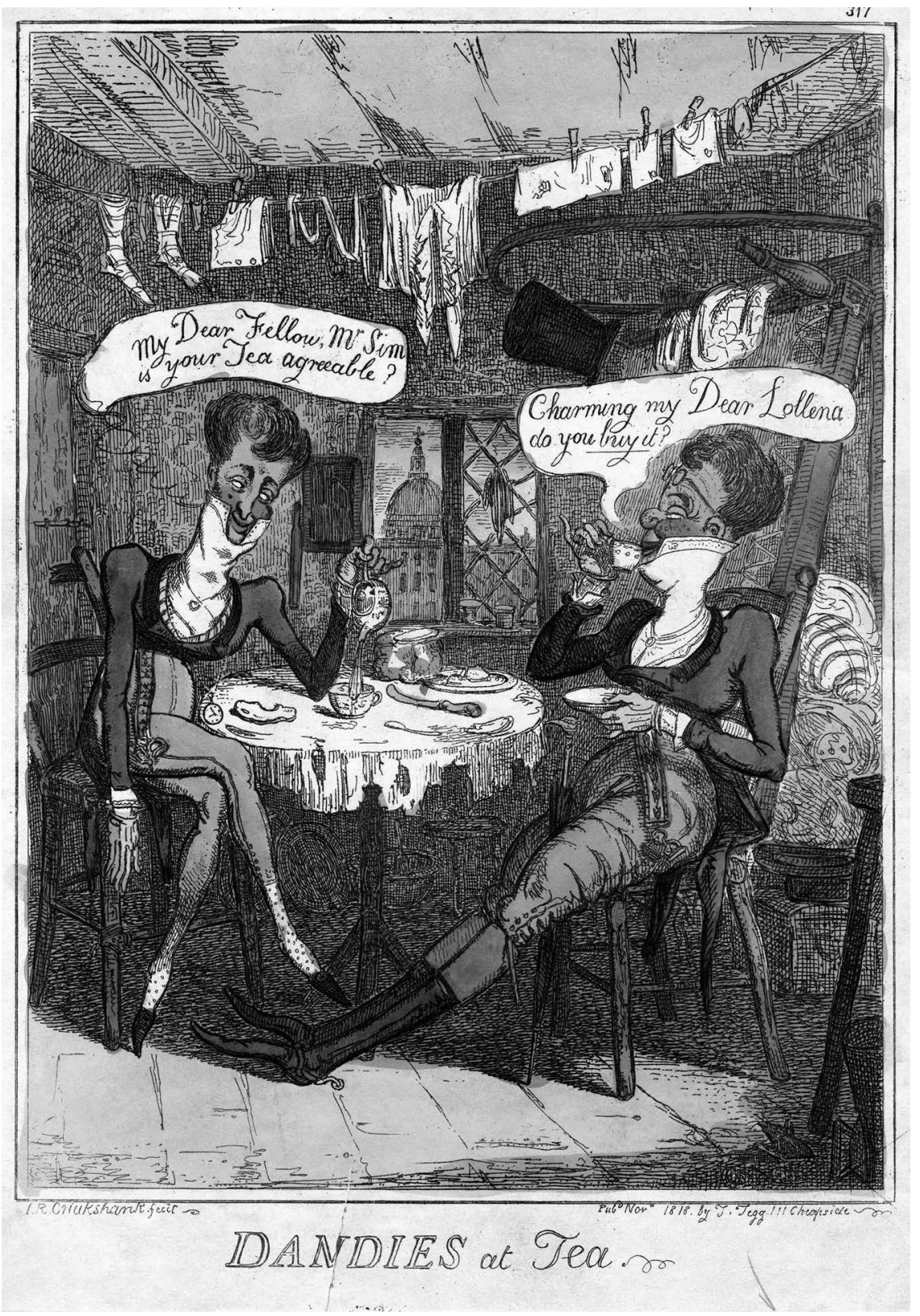

Figure 2. Dandies at tea. (C Trustees of the British Museum.) 
(2) We tead at the vicarage (Lee (1948: 5), citing Jespersen (1924: 52) $)^{4}$

The upshot is that using notional definitions on sentence (1) would allow us to construe tea either as a thing or as an event, which suggests that the choice of $\mathrm{PoS}$ is somewhat arbitrary. Compare lightning, which has no good semantic reason to be a noun, since it isn't really a thing. In Hopi the word for lightning is apparently a verb (Whorf 1956: 215). Or consider fist, also a noun in English, even though it isn't a part of your body the way hand or shoulder or head are: you only have a fist when you make one, which makes it temporary and event-like. Linguists can be very dismissive of notional definitions because it is so easy to show they cannot be what we actually use to identify PoS — or at least, that they're not the whole story.

In the structuralist tradition, notional definitions are dangerous and misguided for use in analysing any given language, but they still have their value in other kinds of linguistics. It's only fair to point out an alternative view, in which semantics is primary, for example in Cognitive Grammar:

The standard doctrine that basic grammatical classes (parts of speech) are not semantically definable rests on erroneous assumptions about the nature of linguistic meaning. With a proper view of meaning, basic categories - notably noun and verbhave plausible conceptual characterizations at both the prototype level (for typical examples) and the schema level (valid for all instances). The prototypes are based on conceptual archetypes: objects for nouns, and actions for verbs. (Langacker 2008)

Likewise in Radical Construction Grammar (Croft 2001, 2005a, b). Even for structuralists they may have a place in cross-linguistic comparison. The prototypical members of the major categories do have a fairly well-defined semantic (or relational) characterisation, and that's what allows us to use the same terms $-\mathrm{N}, \mathrm{V}, \mathrm{Adj}$, and perhaps others - across a diverse range of languages.

\section{How they look: morphology}

When I came back to language at university level, I found myself in what might be called the British development of American structuralism. In this tradition the PoS are not defined by their meaning or their apparent function: in principle, only matters of form can be used. In Latin and Greek and some other languages you can do most of the job by looking at the morphology, a word's internal make-up. So we may judge that splendid and sleepy are Adjectives in (1), since -id and $-y$ are often adjectival endings, recognising that those clues are not infallible (cf. a pyramid, a posy). Many English words don't carry any clues to their PoS in their basic form. What about

\footnotetext{
${ }^{4}$ In most examples I underline the salient word(s).
} 
inflectional endings? That's supposed to be a good clue in general (McCawley 1982: 187), but in Modern English inflections are rather thin on the ground: just a few endings for verbs (and many verbs occur without any), just plural and genitive on nouns (and not all of them), no agreement of adjectives with nouns (all of which is what leads some people to claim-mistakenly-that 'English doesn't have much grammar').

\section{Who they associate with: syntax}

In the model I've been used to in my teaching, syntactic distribution is the key, the range of possible positions for a word in sentence structure. Here inspection is frequently not enough: we have to test the distribution of an element by varying the sentence or creating new sentences to see whether or not the element behaves as we think the putative PoS would predict. In my understanding, a lexical PoS acts as head of a phrase, and it is the syntactic distribution of the phrase above all which tells you what kind of phrase it is. Technically, this is X-bar syntax (Jackendoff 1977, building on earlier work by Chomsky). Thus N is head of NP, and NPs are available to act in various functions, as subjects, objects of various kinds, complements of prepositions, predicative complements:

(3) a. The Phil Soc tea was splendid.

b. I enjoyed the Phil Soc tea.

c. I give the Phil Soc tea full marks.

d. I was yearning for a Phil Soc tea.

e. That certainly is a Phil Soc tea.

The phrase (here an NP) fills a functional slot: the phrasal category and the function are not the same; they label the same item but operate in different grammatical systems.

So we know from its distribution in (3) that the Phil Soc tea or a Phil Soc tea is NP, we know that tea is the head of the phrase (ignoring proponents of the DP analysis), and therefore tea is N. ${ }^{5}$ Similarly Adj is head of an AdjP, V of a VP, Adv (Adverb) of an AdvP. These phrases often have a characteristic internal structure too, which is part of the identification scheme. If you bring in the internal structure, however, then $\mathrm{N}$ and NP are mutually defining, so there is an element of circularity. One way of looking at this is that language is 'un système où tout se tient ${ }^{6}{ }^{6}$ (I'll return to this concept),

\footnotetext{
${ }^{5}$ There is disagreement in formal linguistics as to whether the head of such phrases is the noun or the determiner, a dispute which would take us too far afield; for present purposes I assume the more traditional view that these are NPs with $\mathrm{N}$ as head.

${ }^{6}$ 'A system where everything hangs together.' On the origin of the slogan, due probably to Meillet, see Hewson (1990), Bauer (2003), Koerner (2004: 181 ff.).
} 
so we need to learn PoS together with functions and constituency, because they are mutually defining.

This is a linguist's solution. Once you know how to do it, by and large you can do it. If you feel comfortable with the clear cases, you can then have the confidence to test the non-obvious cases. Or, to put it somewhat unfairly, if you know what answer you want to get, you can get it. But that's exactly why learners can get it wrong. Every kind of evidence has pitfalls and exceptions, and if they don't know what answer they should be aiming for-or are using an illegitimate or mistaken initial assumptionthey may go wrong.

\section{A professional view: The Cambridge Grammar}

How to identify PoS is not a done deal, and to make things worse, there is a wide range of terminology in this field. When you add in the multifarious ways each term is used by different authors, and too often inconsistently by the same author, it becomes quite bewildering. In this morass of possibilities, I prefer to start from something solid:

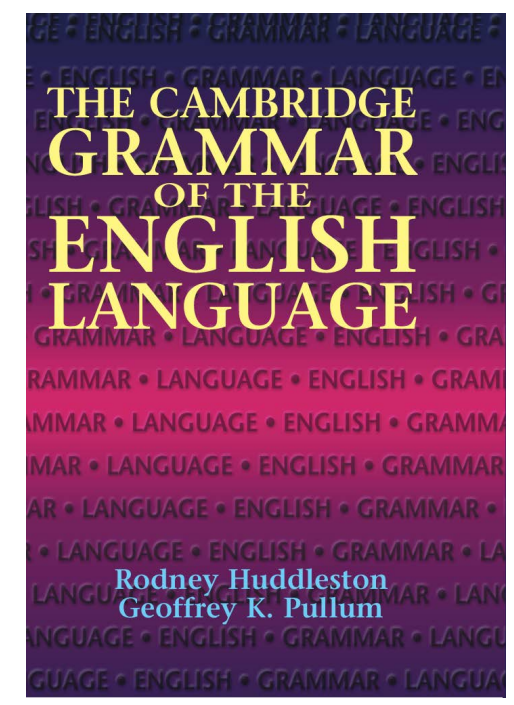

Figure 3. Cambridge Grammar cover, image kindly supplied by Cambridge University Press.

Let's take the carefully argued basis of the Cambridge Grammar of the English Language (2002) (and cf. also Pullum 2009), though I will continue to use word class (their term is lexical category) and PoS interchangeably (Huddleston \& Pullum 2002: 21-2), and employ Determiner (rather than H\&P's determinative) for the word class which includes articles, demonstratives and possessives like $a$, the, this, $m y$. Their word 
classes are not exactly the same as traditionally understood: Preposition, for example, covers much more territory than usual. H\&P use a syntactic analysis which is based on constituency, with each node of the syntactic tree potentially labelled both for its syntactic class (phrasal class or word class) and its function. There is no movement, no empty categories in this analysis. Everything is rigorously argued for, and sometimes more than one possibility is considered. But there is always one analysis which wins out.

\section{The numbers game: how many PoS?}

The Cambridge Grammar settles for nine (2002: 22), roughly the same number-but not exactly the same list - as in many traditional grammars derived from Greek and Latin precursors; Pronoun is a subclass of Noun in this work, for example. In some branches of the Chomskyan tradition, Pronoun is instead grouped with Determiner. Dick Hudson has gone further and suggested that Pronoun and N and D all belong together as one supercategory (1990: 268-76).

Giegerich (2012) has recently argued (contra Payne, Huddleston \& Pullum (2010) but with Emonds (1972), Radford (1988)) that adverbs are merely a kind of Adjective, so that a separate word class Adv is not justified. Feist (2012), on the other hand, argues that Adjective is an unworkable category! (It is senses, not words, that should be categorised, says Feist, and new classes have evolved in the last 600-800 years.) In the Chomskyan tradition we see two tendencies: abstract grouping using binary features $[ \pm N],[ \pm V]$, lexical vs. functional, etc., and a proliferation of specifiers or subcategories.

In my work I often make use of (and indeed have helped to construct) linguistic corpora. A corpus is a systematic collection of linguistic data. Builders of corpora routinely attach PoS tags to words as a step towards parsing and/or as an aid in computer searches for linguistic patterns, and the granularity of their PoS tagging is routinely much finer: the Penn Treebank uses 35 PoS tags, the CLAWS5 tagset from Lancaster has 58, CLAWS7 137, CLAWS8 159.7

I won't be addressing these questions directly, merely noting that lumpers and splitters can argue the toss about the number and membership of word classes in English - whether on theoretical or on practical grounds-and that's without moving on to human language in general (e.g. 'Do all languages have the class Adjective?'). We are at least entitled to be sceptical about claims for some universal set of word classes. So I will settle for the Cambridge Grammar and its choice of nine PoS for English.

${ }^{7}$ I have counted neither punctuation tags nor 'ambiguity tags'. 


\section{PART 2: CHANGE OF IDENTITY}

The Cambridge Grammar is not a historical work. It gives a picture of current, or at least recent, English. If we take a historical perspective, though, we know that words from one word class can come to be used as another, by derivation or by conversion.

\section{Quick change: derivation and conversion}

Thus when a noun is needed from the verb invite (1533- $),{ }^{8}$ there can be a new derived word (invitation, 1602- ) or the verb can be converted more or less unchanged into a noun:

(4) Everybody ... accepted the invite

Example (4) is the kind of sloppy usage you would expect from someone in their twenties, though the fuller citation (4)' may surprise some readers; this particular conversion is of long standing:

(4)' Every body Bowed, \& accepted the invite but me..for I have no Notion of snapping at invites from the Great. (1778, Fanny Burney, OED)

(5) Bishop Cranmer..gives him an earnest invite to England. (1559, OED)

There is considerable freedom in English to change word class by conversion, especially $\mathrm{N} \leftrightarrow \mathrm{V}$. Here are two recent examples, one based on a native compound and one on a borrowed word:

(6) a. [ . . ] with news about players and games available on the front page and player stats and analysis behind the paywall. (2004, OED)

b. But at the moment I prefer, if we can, to stay focussed on the immediate issue - donating that reviewing labour to journals that will paywall the results. (1 Oct. 2011, WebCorp)

(7) a. sudoku n. $(2000-, O E D)$

b. Tom and I caught up with our various blogs while Neil Sudokued. (15 May 2006, WebCorp)

In this paper I am not discussing conversion any further, because it seems to me to present no difficulties for any standard approach to word classes. If there is an identity switch, it applies to the individual word. The word classes are solid citizens completely unaffected by the fact that they can gain new recruits.

\footnotetext{
${ }^{8}$ Dates from $O E D$.
} 


\section{Gradual change: $\mathbf{N}>$ Adj examples}

Noun and Adjective are distinct word classes which nevertheless share some defining features; see Table 1. If $\mathrm{N}$ and Adj were solid citizens, that is, well-behaved Aristotelian categories, then any given word would either have all the right properties for $\mathrm{N}$ or all the right properties for Adj. Conversion would instantaneously create in effect a new word with the properties of the other class. That's what happened with bitter (beer), daily (newspaper), etc., which by ellipsis developed a new Noun use alongside their existing Adjective use.

But maybe the word classes are more slippery than that. Why should all the defining properties be adopted at once? It may well be that while $\operatorname{Adj}>\mathrm{N}$ is instantaneous, $\mathrm{N}>$ Adj can be stepwise.

Parade examples: fun and key

These words are also considered together by, among others, De Smet (2012: 621-8), Kiparsky (forthcoming).

\section{Fun}

As a noun, fun isn't particularly old. It is recorded twice, 1699, 1719, as a countable noun in senses like 'trick, hoax'. Then from 1727 it appears apparently as a mass noun. ${ }^{9}$ The first two mass-noun citations in $O E D$ are interesting:

(8) Tho' he talk'd much of virtue, her head always run Upon something or other she found better fun. (1727, Swift) [context is 10-line humorous 'Epitaph of By-words']

(9) Partridge..was a great Lover of what is called Fun. (1749, Fielding)

Table 1. Noun vs. Adjective.

\begin{tabular}{lccc}
\hline & $\mathrm{N}$ & Adj \\
\hline X takes D as dependent (the man, some people) & + & $?-$ \\
XP can be subject, direct object, indirect object, complement of preposition & + & - \\
X can postmodify N (a politican greedy for power) & - & + \\
X takes intensifier as dependent (very big, so dangerous) & - & + \\
X can premodify N (bad habits, coal strike) & + & + \\
XP can be predicative complement & + & + \\
[various features characteristic of V, e.g. tense] & - & - \\
[various features characteristic of other PoS] & - & - \\
X inflects for plural (three strikes, the children) & + & - \\
X inflects for genitive (the boycott's impact) & + & - \\
X can be marked for comparative and superlative (heavier, more dangerous) & - & + \\
\hline
\end{tabular}

${ }^{9}$ But note this late use of countable fun:

(i) and his explosions of laughter were as loud as usual, when Becky, with a fun which she could not disguise, even though it was at her own expense (1843 Thackeray, Vanity Fair, CLMET 3.0). 
The Tom Jones quotation (9) clearly suggests that the usage was then new-fangled, and $O E D$ (s.v.) notes that 'Johnson 1755 stigmatizes it as "a low cant word"; in present use it is merely somewhat familiar'.

There are several factors making fun a slightly special case. It is a mass noun and so occurs freely without a determiner, which means that the complement in examples like

(10) Oh, farmer, such lies are very witty, though you and I don't just now like the wit of them. This is fun, this is quizzing; but you don't know what we young gentlemen mean by quizzing. (1796-1801, Edgeworth, The Parent's Assistant, or Stories for Children, CLMET 3.0)

(11) But we know we do not love scandal, but fun; and if scandal happens to be fun, that is no fault of ours. (1820, Keats, CLMET 3.0)

looks indistinguishable from an AdjP (cf. This is nice, if scandal happens to be available). It is in fact an NP, as neighbouring clauses in both these early examples make clear. The noun fun is semantically gradable (not much fun, great fun), which is a semantic property associated with adjectives, albeit manifested with different intensifiers.

Later, fun turns up in the other place where both $\mathrm{N}$ and Adj are permissible, as prenominal modifier:

(12) There was a room at Holly House called the 'fun-room', without chair or table. (a1846, OED)

(13) Fun jottings; or, Laughs I have taken pen to. $(1853$, OED)

(14) The three Miniver children and the four younger McQuerns went because of the Fun Fair in the next field. (1940 Jan Struther, Mrs Miniver, COHA but actually British)

It is still a noun in these examples, but for how long?

What if you actually need an adjective based on fun? The obvious, existing derived adjective, funny, had long been recruited for meanings that don't simply mean 'enjoyable, causing pleasure': the 'amusing, funny ha-ha' sense is found from the start, 1756(cf. the meaning of the countable noun fun), while the 'curious, funny peculiar' sense joins it from 1806- . So funny is blocked as having the wrong meaning. Other suffixes don't seem to have been tried. People simply used fun without any suffix as an adjective. Why not? There's nothing about its shape which makes it look more like $\mathrm{N}$ than Adj. But when was it that this first happened?

There are uses which are more suggestive of adjective status:

(15) It was really fun. $(1960$, COCA) 
(16) so that the hobby, which often proved fatal, would be safe as well as fun. (1966, TMC)

They are not conclusive, however: really in (15) could be a VP adverb rather than an AdjP intensifier, while the coordination of (16) doesn't prove that both conjuncts are from the same word class (cf. He was a lecturer and on strike and very angry, which successfully coordinates NP, PP and AdjP).

Over fifty years ago, John Algeo (1962) noted that fun had been recognised by the 1961 Webster's Third as having an adjectival use. The evidence in Webster's and in Algeo's article seemed to consist solely of premodifying examples ${ }^{10}$ like a fun party, fun hat, a fun night, have a fun time (s.v. ${ }^{3}$ fun adj.), though Algeo relies on spoken examples with a stress pattern more characteristic of adjectives than nouns, which is a little more convincing. His conclusion is witty and wise:

The future development of adjectival fun needs watching. We can surely expect to find pure intensifiers used with it: a very fun party is only a matter of time. We may even anticipate being told that one car is funner than another, and that will be the funnest thing of all. (Algeo 1962: 159)

Bolinger (1963) followed this up the next year when a teenaged member of his family used so fun, which he clearly found notable. Nowadays so fun rather than such fun is quite normal in the speech of twenty-somethings in the UK. Algeo's predictions have all come true, mostly some thirty years after he published them (although note the early date of (17)). ${ }^{11}$ Here are some examples where fun must be an adjective:

(17) Doing something fun like redecorating your room..is really interesting biz for a teen who loves being busy. (1951, OED s.v. teen n.2)

(18) Andrew and I are having a very fun time together, yes. (1988, COCA)

(19) a. And they are so fun to eat! (1979, COHA)

b. [. . .] to a place as fun and earthy as a mud fight. (1990, COCA)

c. Don't be too worried if the software seems too fun to be educational. (1993, COCA)

(20) a. Walking and looking is boring. Touching is funner. (1990, COCA)

b. It used to be buying clothes was one of the funnest things in the world; now it's more a necessity. (1990, TMC)

c. It's been killer! We're almost a month into the tour now. The last time we did their tour was about six years ago, I think, and it was probably one of the funnest things we've ever done. (2012 http://metalassault.com/

\footnotetext{
${ }^{10}$ Older entries in the $O E D$ also sometimes confuse premodifier with adjective.

${ }^{11}$ Kiparsky (forthcoming: n. 17) has now found some probably adjectival examples of fun as early as the first decade of the 20th century.
} 
Interviews/2012/11/10/devildriver-frontman-discusses-north-american-tour-new-material/, att. Marianne Hundt)

Both from the earliest attestations I have so far been able to find, and from introspection, I don't think all the adjectival properties arrive in one fell swoop. I'm fine with (17) and probably (18), but not with (19) or (20). Fun was and is a noun. For some speakers it can also be an adjective. And the adjective use arrived in the language stepwise. I will come back to this.

\section{Key}

In its core meaning, key is a concrete, countable noun for that which unlocks (a door, a file, a code). The $O E D$ has recently (March 2013) revised its entry. There are two figurative extensions which are important here. One rather predictable one, found from the very earliest historical period, is '[a] means of understanding something unknown, mysterious, or obscure; a solution or explanation' (OED s.v. key n. ${ }^{1}$ and adj. A. 5a):

(21) It was the key to his success $(1883$, OED)

For brevity I will call this abstract meaning 'explanatory'.

In the revised entry, another figurative sense of the noun is '[a] person who or thing which is central to a system, group, or organization; an essential or key element; a mainstay' (s.v., A. 6), from 1559-, and the architectural term keystone may play a part in this development:

(22) Mathematicks are the Key of true Physicks. (1724, OED)

I will call this sense 'essential' for short. Sometimes, as with (21), 'explanatory' and 'essential' are hard to distinguish. In any case, morphosyntactically key is still countable.

Like all nouns, it can be used as a premodifier. At first probably it does so in simple definite NPs:

(23) Progress at Charleston-The Key Position of the Opening Campaign (1860, NY Herald, 19CAmNews)

(24) But the key man of the mystery was missing, Patrick Eugene McDermott, exconvict, member of a family of mine-laborers in Nanty Glo, Pa. (1926, TMC)

Later it is used as modifier in NPs without definite article:

(25) Spray-dried flavors are key ingredients of a new tableted carbonated drink concentrate. $(1958, O E D)$

(26) In addition to illness, homelessness is a key issue. (BNC) 
For key, it seems safe to assume, premodifying contexts are the locus of transition to adjectival usage, which the $O E D$ now dates to $1832-$, though it comments that '[b]efore the mid 20th cent. often hyphenated and prob. construed as an attributive use of the noun'. Still, $O E D$ has found a predicative use from 1877-a very early one, as that usage only takes off from the mid-1960s. The meaning given is '[o]f paramount or crucial importance; dominant, chief, essential' (s.v., B), and it seems to be a minor extension of the 'essential' sense in the noun.

(27) a. [ . . ] this kind of work, which is key to sustaining me through day-to-day resistance and pressure to stop (1965, COHA)

b. Versatility is key. (1977, TMC)

c. Groove is key, but it's not the whole enchilada (1993, OED draft additions June 2008 [no longer in this $O E D$ entry])

In predicative use of this kind, key appears without an article. There is no uncertainty as to category: bare key is an AdjP in (27), since it could not appear in any other position characteristic of NPs.

In much of the data currently available to me, it takes another thirty years or so before other evidence of adjectival status starts to appear, though Turo Vartiainen has pointed out one early example, (28)a (pers. comm. 21 Aug. 2012). We have modification by very, so, as or too (28), coordination with or substitution of another adjective (29) and (30)b, postmodifier use (29), and both syntactic (30) and morphological (31) comparison:

(28) a. I think the role of the Ambassador in the Soviet Union is a very key one (1964, COHA)

b. I think this is so key. I mean, it's what every study has ACTUALLY found (n.d., ANC2)

c. Ongoing education may be just as key as more stringent certification requirements. (1998, COCA)

d. it was too key a nation to us to take a very strong stand on (1999, COCA)

(29) and it's something key and crucial that I have learned in my life. (1996, COCA)

(30) a. So therefore that was more key to you than [...]? That was more important to you? (1995, COCA)

b. It's the most key part of this business. If you don't make the right decisions, you can lose a considerable amount of money [ . . . (1998, COCA)

(31) a. I think my key point is going to be this: girls are not wired to do that kind of stuff . . . and an even keyer point is the definition of 'stuff' (Blogzkrieg, 19 Apr. 2005)

b. Mirror, mirror on the wall, who's the keyest of them all . . (31 Jan. 2001 http://www.purplehunt.com/usedclues.htm) 
Are these words special cases?

We have seen that fun had a number of properties that facilitated the transition to Adj, first as a predicative, while key too got there, probably first in attributive position. These two words have been noted and studied by several scholars. Perhaps they're just one-offs. The Cambridge Grammar thinks so, and a lot of experts assert that this kind of $\mathrm{N}>$ Adj transition is otherwise vanishingly rare, apart from the well-known pattern of material nouns like stone (wall), glass (jug): Marchand (1969: 361), Huddleston (1984: 328), Quirk et al. (1985: 1562), Haspelmath (1998: 329), Huddleston \& Pullum (2002: 536-7, 1643). The Estonian scholar Oleg Mutt (1964: 345-6) wrote that for 'the present time' (early 1960s), 'there does not seem to be any marked tendency to form adjectives from homonymous nouns', although the words highbrow, lowbrow and wizard are mentioned (1964: 346-7). Perhaps it was true then. It isn't true anymore.

Incidentally, these matters have been debated by the Phil. Soc. before. Richard Morris and Frederick James Furnivall argued at the Philological Society in London that cannon in cannon ball was an Adjective, while James Murray and Henry Sweet dissented. This was on 1 April 1881 (Jespersen 1909-49: II 310). What goes around comes around. Here the PoS controversy intersects with questions of syntax vs. word formation (Is cannon ball one word or two?); see further below on prefabs. Another possible test which is at least indicative of adjective class membership is the possibility of suffixation by -ness (Scott Collier, pers. comm. 13 May 2013).

\section{Other $N>$ Adj}

Semantically very similar to key is core, which seems to be going down the same route. The $O E D$ entry notes an attributive use of the noun 'passing into adj.' 1935- (s.v. core n. ${ }^{1}$ 16), when core curriculum is attested, but one can now find uses like the following: ${ }^{12}$

(32) 'It is very core to our program strategies and is integrated throughout out [sic] all of our work,' she said. (2011, Chrissy Faesen, quoted by Chantal Tode (24 Oct.) http://www.mobilemarketer.com/cms/news/database-crm/11294.html (accessed 6 Dec. 2011))

(33) a. '. . and so that idea of how things stay together is very core to who I am'

b. 'Bach is completely core for me' (2012, Edmund de Waal, Desert Island Discs, BBC Radio 4 (25 Nov.))

Other examples I have tracked include bandaid, dinosaur, draft, freak, genius, niche, pants, powerhouse, rubbish, Velcro. There are dozens more, including ace, amateur, apricot, cardboard, champion, corker, cowboy, killer, landmark, luxury, surprise, working

\footnotetext{
${ }^{12}$ I came across this new use of core thanks to my student Sarah Mullings, who used it on 6 Dec. 2011.
} 
class; Mutt has examples from early times up to the mid-20th century (1964, 1967, 1976), and Marianne Hundt and Hendrik De Smet have added recent examples (pers. comms. April-May 2013).

(34) Richard represents views that myself and those who work in the business of football find totally dinosaur. (2011, Karren Brady, London Evening Standard (27 Jan.) http://www.thisislondon.co.uk/standard-sport/football/article23917849-karren-brady-aims-parting-shot-at-dinosaur-richard-keys.do (accessed 23 Feb. 2011))

(35) It's been killer! $(2012=$ example (20)c)

(36) It's extremely draft (I think Tom wanted me to post it as an article). (2006, http:// lxer.com/module/forums/t/22188/ (24 Mar.))

(37) I think that this song has some very genius and touching lines. (2002 (18 Apr.) http://www.songmeanings.net/lyric.php?lid=146705 (accessed 3 Nov. 2009))

(38) The nichest of the niche (2005, http://www.1up.com/do/my1Up?publicUserId=5455111 6.01.2005 (accessed 3 Nov. 2009))

(39) a. Secondly, browsing to Windows shares in Nautilus doesn't work. Not even a little bit. [. . .] This is also very pants indeed. (2004, http://www.kryogenix. org/days/2004/11/05/fawkes, 5.11.2004 (accessed 2 Nov. 2009))

b. Just wondering if anybody else ever feels like they don't have the skill/ strength/brains/ability to teach. Currently feel like the pantsest teacher in the world - is this normal or am I really just rubbish? (2006, http://community. tes.co.uk/forums/t/926.aspx, 31.03.2006 (accessed 2 Nov. 2009))

\section{Word order}

Remember that our primary criterion for assigning PoS is the syntactic distribution of a word. A formula for one common kind of NP with premodification of the head noun might be something like

(40) Determiner Adjective(s) Modifying Noun(s) Head Noun

Modifying adjectives precede modifying nouns, ${ }^{13}$ as illustrated in Table 2 (where the asterisk indicates ungrammaticality). This apparently gives us another diagnostic for adjectivehood, since a modifier occurring to the left of something which is a clear adjective is probably (we assume) also an adjective. When a noun is suspected of developing adjectival tendencies, we might expect it to start migrating leftwards in

\footnotetext{
${ }^{13}$ I'm not in fact convinced that this rule can be upheld, as other factors may override it, but it works most of the time. On the wider question of whether grammaticality judgements on isolated phrases or sentences are either clear-cut or reliable (often they are neither!) (see below, n. 15, and Denison in prep.: chap. 1).
} 
Table 2. Examples of premodification.

\begin{tabular}{llll}
\hline Determiner & Adjective zone & Modifying noun zone & Head noun \\
\hline a & big & tourist & attraction \\
a & garish big expensive & London tourist & attraction \\
$*_{\mathrm{a}}$ & tourist & big & attraction \\
\hline
\end{tabular}

NPs that obey the pattern shown in (40).

And that's exactly what we do see. Consider powerhouse, a noun found from 1870 that develops a figurative sense (1908- ) '[a] source of energy or inspiration; a strong or powerful person or group of people' (OED s.v., 2a). It is recorded as an adjective by $O E D$ from maybe 1928 in sport and 1937 in music, though convincing adjective syntax comes a bit later. As for word order, examples (41) early on in the process show powerhouse acting as a modifier, in sport and music contexts, respectively, but always next to its head noun.

(41) a. Few fans, however, were prepared for the powerhouse offensive that Michigan uncorked. (1938, TMC)

b. Raves coming thick and fast for George Auld's new powerhouse band now at the Arcadia Ballroom, N.Y. $(1942$, OED)

Example (42) is more recent, and by now we can be fairly sure from the word order that powerhouse has developed a full adjectival use:

(42) The powerhouse new bestseller from ELIZABETH GEORGE (1996 Bantam Press advertisement, The Guardian, p. 1 (3 Feb.))

(43) So we get another injured player. Broken right toe? Guess that's better than Stewart's wrist injury. BUT he doesn't sound like a very powerhouse player. (2013, WebCorp, http://muskat.mlblogs.com/2013/01/02/12-schierholtz-the-man -in-rf/ (2 Jan.) (accessed 6 May 2013))

The use of very as intensifier in examples like (43) confirms the arrival of full adjective syntax.

\section{Other gradual PoS changes}

$\operatorname{Adj}>D$

We can use the diagnostic of position to show that there is a pathway leftwards out of the adjective slot(s) into the determiner slot(s) (Denison 2010). Words like certain, various, several start off as adjectives, and the first two can still act as Adj (present-day examples are taken from the BNC): 
(44) a. but I'm not certain

b. the infinitely various capacities of children

c. Thus when a childe hath got the names of his letters, \& their several shapes withall in a playing manner, he may be easily taught to distinguish them in the following leaf. (1660, HC, from Breban (2008: 280))

Their semantics change to include senses much more typical of determiners, such as quantifiers: several as 'a vague numeral' and various 'as an enumerative term' (OED). They start to appear in positions which could only be occupied by determinerpronouns and not by adjectives, as in the so-called fused head construction of (45) (Payne \& Huddleston 2002: 410-12). Compare (46), which shows that adjectives do not normally share this behaviour with determiners:

(45) a. certain of our great cities

b. various of these approaches

c. several of the papers

(46) a. some/those/many/all of the papers

b. *popular $/ *$ unscrupulous $/ *$ small $/ *$ British of the papers

\section{Yet more PoS changes}

Other PoS changes, which I have no space to discuss, include:

$$
\mathrm{V}>\text { Adj }
$$

(47) a. much interested

b. very interested

Adv $>$ Pron

(48) a. The castle is there.

b. There'll be a solution, won't there?

$\mathrm{P} \sim$ Adj: the direction of change can vary, as with like, worth

(49) a. near the station (cf. in the station)

b. very near (cf. very distant)

c. very near the station

$\mathrm{V}>$ Aux/M: the development of modal and other auxiliaries out of verbs Prep > no category > Aux: the much-debated PoS of the infinitive marker to

\section{PART 3: THEORETICAL APPROACHES}

Other things being equal, we might prefer to have a unique, unequivocal analysis for every grammatical sentence in the language. For many linguists and many lay folk too, 
this desideratum becomes an inviolable requirement. I want to demote it to a less dominant position in our priorities by allowing two possibilities to override it when necessary: underspecification and dual analyses.

\section{Dual analyses}

This perhaps covers several different ideas. One is intermediate or mixed categories. These have a long history.

Figure 4 is the illustration I used in the Academy promotional material, from a Victorian children's book, and shows a very decorous tug-of-war between Mr Adjective and Mr Pronoun over the word her, which they both claim (Nesbitt 1889: 45-51). ${ }^{14}$ In those days, most determiners weren't distinguished from adjectives. After some questioning of the two claimants by Serjeant Parsing, Judge Grammar gives the Solomonic ruling that her and a whole slew of other function words are in fact 'Adjective-Pronouns'.

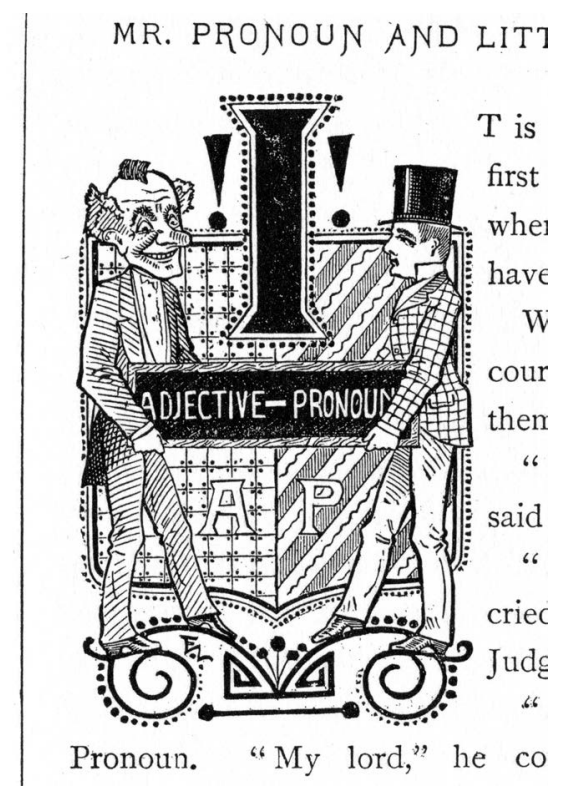

Figure 4. Tug-of-war (from Nesbitt 1889).

\footnotetext{
${ }^{14} \mathrm{Mr}$ Adjective is a chatterbox and gossip (of course), while Mr Pronoun is a hard worker (he often stands in for Noun!), but both are solid-looking citizens; Article, though, is a barefoot lad, and Interjection is a bit of a scamp.
} 
Mixed categories are available in several serious modern linguistic theories, e.g. Principles \& Parameters and Minimalism and HPSG (Rauh 2010: 147, 200). In some conceptions the mixed category would be associated with a mixed syntactic structure, though most theorists hate such an idea, and I haven't seen it worked out in detail.

Another idea is dual (or multiple) inheritance, whereby a linguistic item inherits some of its properties from more than one source. This is possible in a word-based network theory like Word Grammar (Hudson 2006), in many versions of Construction Grammar (e.g. Croft 2001, Goldberg 2006), and you even get 'multidominance' in some offshoots of Chomskyan Minimalism. Many years ago, long before I'd heard of Optimality Theory, I wrote:

Rather than a given sentence being the output of some maximally simple, elegant, and maybe unique rule, I regard a sentence as the more likely, the more (potentially conflicting) requirements it satisfies simultaneously, thus the more patterns it matches. (Denison 1986: 293)

And a third idea is that the grammar of an individual speaker or of a language is not necessarily wholly internally self-consistent or coherent. As I wrote a bit more recently:

However, there is another view of economy which suggests that an individual speaker need not have a wholly consistent grammar. It may be - in my view, it may well bethat speakers are capable of routinely using fragments of language which are mutually inconsistent. Speakers may in part organise language at a much more local level. The patterning involved may be less neat but not necessarily more complex. This would be a bottom-up model. The view that an individual's grammar may not be homogeneous is subscribed to by, among others, Harris \& Campbell (1995). Croft (2000: 231) quotes a nice line by Bolinger: 'I want to suggest that language is a structure, but in some ways a jerry-built structure' (1976: 1). (Denison 2001: 121)

In support of inconsistency see for example Bybee \& Cacoullos Torres (2009) and various linguists who have advocated usage-based models of learning and change, which are inherently prone to piecemeal, local innovations; a comprehensive recent discussion is Bybee \& Beckner (submitted). Dick Hudson, writing on the benefits of a cognitive analysis, makes this observation:

but perhaps the most important attraction for a linguist is the possibility of facing uncertainty and complication in the data without feeling obliged to arrive at a single coherent and complete analysis. If a multiple, messy and incomplete analysis is good enough for a language learner, it should certainly be good enough for us. (Hudson 2013: 149)

A lot of linguistics seems to be a quest for a perfect validation of the human mind, or at least, its language faculty. If we can only attain full understanding, the argument seems to run, we will see that language is 'un système où tout se tient': one system 
(rather than 'a system') where everything hangs together. But I doubt that it is actually one system even for the individual speaker. Attempts to fit all the pieces together make the model more and more arcane, like a Ptolemaic astronomer trying to save the elegant idea that heavenly bodies move on spheres around the earth, and having to add more and more epicycles as observations get more precise. Anyway, it seems misguided to aim for a perfectly economical model of something that has so much redundancy in it. For language as a social construct, surely no one could claim that there is just one system. There is variation between speakers, and there is change.

\section{Gradience and underspecification}

For the sentence

(50) It was fun.

it depends who said (or wrote) it. Imagine three speakers: ${ }^{15}$

Speaker1 (more conservative) only has fun as N

Speaker2 (less conservative) accepts something fun, really fun but not so fun, very fun, funner

Speaker3 (advanced) has fun both as $\mathrm{N}$ and as Adj

If used by Speaker1, (50) contains $f_{u n}$. End of story. If used by Speaker3, who has both $f u n_{\mathrm{N}}$ and $f u n_{\mathrm{A}}$ in their repertoire, then (50) could equally have fun as $\mathrm{N}$ or Adj. The speaker doesn't need to decide which. The hearer doesn't need to decide which. It is not ambiguous (in my terms), as nothing at all hangs on the choice between $\mathrm{N}$ and Adj. So I claim that the linguist doesn't need to decide which either - and indeed can't decide in any non-arbitrary way. For me, ambiguity would be when the analyst lacks knowledge which the speaker/writer could have provided, and which would decide between different possible readings, but the meaning of (50) is the same either way, as is the structure (apart from the label on the phrasal and lexical nodes of the predicative complement). It's not ambiguous.

Semanticists routinely distinguish between ambiguity and vagueness. Standard examples to bring out the distinction are:

(51) Duck or grouse. [ambiguous]

(52) Jan killed her husband. [vague]

\footnotetext{
${ }^{15}$ I had forgotten when I first wrote this section that Ross, struggling with the notion of dialect, mused on how speakers will vary in how 'stingy' or 'generous' they will be in accepting particular sentences (Ross 1973: 389-91 [2004 reprint]). He was concerned there purely with synchronic variation among idiolects, but there are clear similarities in the thought-experiments.
} 
Example (51) either mentions two kinds of bird, or it contains two imperative verbstypically as a jokey warning placed on a low beam in a pub. Out of context it is ambiguous. Now (52) doesn't tell you whether the killing was intentional or accidental, but it isn't ambiguous, it's merely underspecified or vague in that regard. The semantics of the verb kill just don't specify intentionality when there's a human subject-and indeed the verb can also be used with an inanimate subject. I suggest that the same distinction between ambiguity and vagueness could usefully be employed in syntax. Example (50), when used by Speaker3, is underdetermined or vague. ${ }^{16}$ No violence is done to the idea of PoS in these circumstances, since in general elsewhere there is a serviceable distinction between $\mathrm{N}$ and Adj. The fact that occasionally they cannot be distinguished is OK. On this view, the status of fun in (50) can't be stated for English as a whole but only for the individual whose grammar we are trying to model: English has more than one grammar available.

Similar arguments can be made for fun in (53) or key in (54):

(53) They had a fun day on the river.

(54) They had a key idea for the analysis.

However, the sentence

(55) It was key.

must have key as an adjective, since key as a noun is countable and would need a determiner.

I've discussed my hypothetical Speaker1 and Speaker3. Returning to

(50) It was $\underline{\text { fun. }}$.

we haven't dealt with Speaker2, who allows some non-noun-like behaviour of fun but not the whole adjectival enchilada (and speakers may differ on precisely what they do and don't accept here). How do we model that? Speaker2 is not a figment of my imagination, by the way. I think it's me, for example. And I have some relevant elicitation data for another word, rubbish, where informants accept some but not all signs of adjectivehood (Denison 2010: 110-11).

Haspelmath casually suggested that words which behave like this should be given a fractional PoS, illustrating it with a cline from verb $(\mathrm{V})$ to preposition $(\mathrm{P})$ :

Eventually formal grammar will have to allow for gradience of membership in wordclasses by introducing graded notations, for instance $\mathrm{V}_{1.0}>\mathrm{V}_{9} / \mathrm{P}_{1}>\mathrm{V}_{8} / \mathrm{P}_{.2}>\ldots>\mathrm{V}_{.1} / \mathrm{P}_{9}$ $>\mathrm{P}_{1.0^{\circ}}$ (For constituency representations [. . .], similar gradualness of phrasal nodes would be required.) (Haspelmath 1998: 330)

\footnotetext{
${ }^{16}$ Dick Hudson sees a potential problem with conflicting supercategories (pers. comm. 12 July 2013); see further (Denison in prep.: chapter 2).
} 
That is a little bit like John Anderson's Notional Grammar (1997 and other papers), in which any given category is assigned a fixed point on a scale from complete $\mathrm{N}$ (Referentiality, nominality of proper name) to complete P (Predicability, finite verbality).

Well, apart from the rather arbitrary numbers of Haspelmath's decimals or Anderson's ratios, I think this would be missing the point of my data. We could say much more simply that for Speaker2, fun is a Noun in contexts where only $\mathrm{N}$ is possible (a lot of fun), an Adjective where only Adj is possible (something fun), and once again underdetermined/vague in contexts where either would fit.

There are two important points in the idea of a stepwise progression from noun to adjective. It demonstrates genuine gradience between $\mathrm{N}$ and $\mathrm{Adj}$, and it strongly supports the idea that word classes are prototype-based rather than Aristotelian. Deutscher (2005: 277-85) has an elegant dialogue to explain this kind of gradual change over time, emphasising the role of the whole syntactic unit rather than of individual words, while Kiparsky (forthcoming) endorses a two-step process of $\mathrm{N}>$ Adj for fun and key and tries to reconcile it with other theories of language change (such as the Constant Rate Effect). Of course Aarts (2007) is a whole book devoted to syntactic gradience, albeit mainly from a synchronic point of view. What I see as stepwise progession may lead me to prefer an analysis which privileges constructions and makes word classes secondary, but I won't pursue that here: I'm not sure yet that there would be fewer loose ends if we started from constructions.

\section{Community of speakers}

Much historical work assumes competition between conservative and innovative variants of some variable, often producing an S-curve of change (Denison 2003): slow start, rapid spread, slow completion. Two variants implies two kinds of speaker, but with stepwise change we have Speaker1, Speaker3 and possibly various kinds of Speaker2 all co-existing at a given time. A corpus of examples will contain data produced by all of them, and often we won't know which kind of speaker was responsible. The only times we can be certain what kind of speaker we have are before the innovation starts, when there are only Speaker1s, and after the most innovative forms arrive on the scene, which can only be produced by a Speaker3.

What you would expect to see, and do, if the innovation is one that catches on and becomes successful, is an early period where only $\mathrm{N}$ is found, then an increasing attestation of examples whose analysis is - or could be-vague, and only later the appearance of examples that must be Adj. I don't think there is any reason to expect a corresponding decline in N-only examples. In community terms, you would expect Speaker2s to increase in numbers at the expense of Speaker1s, and Speaker3s at the 
Table 3. Speaker types and their linguistic output.

\begin{tabular}{llll}
\hline & $\begin{array}{l}\text { Examples that } \\
\text { must be } \mathrm{N}\end{array}$ & $\begin{array}{l}\text { Examples that could be } \\
\text { vague N } \sim \text { Adj (but } \\
\text { N for Speaker1) }\end{array}$ & $\begin{array}{l}\text { Examples that } \\
\text { must be Adj }\end{array}$ \\
\hline Speaker1 & + & $?+$ & - \\
Speaker2 & + & + & $?$ \\
Speaker3 & + & + & + \\
\hline
\end{tabular}

expense of Speaker2s. However, in a historical corpus we usually only have aggregate data from many speakers, and since you can't correlate data types with speaker types well enough, this scenario is probably not amenable to mathematical modelling by speaker, only by data. For historical corpus work, I think this picture of speakers (or grammars) must remain merely a thought-experiment, but it's a psycholinguistic experiment I'd like to conduct with living informants.

\section{Gang membership or sneakiness?}

Bolinger (1963) discusses what makes fun particularly prone to $\mathrm{N}>$ Adj change, including being a mass noun open to hyperbole, and then discusses other nouns taking a similar route:

As an isolated case, fun might have had trouble passing over. As a member of a large group of mass nouns exerting a steady pressure on the adjective-noun wall, its chances were better. (1963: 238)

How would this work? It's not obvious to me that it would be easier for many nouns to become adjectives together than just one at a time.

Hendrik De Smet's account of language change (ostensibly of reanalysis, though he downplays the role of sudden restructuring) suggests that new uses of a word take advantage of the collocational preferences of existing uses (De Smet 2012: 625-8), and Marianne Hundt (2013 and pers. comm.) formulates this as lexical items undergoing change being slotted first into an established expression, then spreading into neighbouring constructions - what she calls 'constructional bootstrapping'. See also Bybee \& Beckner (submitted: §3.1, citing Wilson 2009). De Smet argues that key as a predicative adjective is significantly associated with occurrence with a to-phrase, though his graph of recent development, reproduced as Figure 5, seems to suggest that the to-phrase is no longer so important (2012: 626-8). The more important of his two complementary explanations for the early incidence of to-phrases is that a to-phrase is a frequent accompaniment of the noun key in metaphorical use - in fact, he says, 87 out of 96 examples from the 1970s in COHA, presumably as in

(56) Communist China is the key to the future of Indochina. (1971, COHA) 


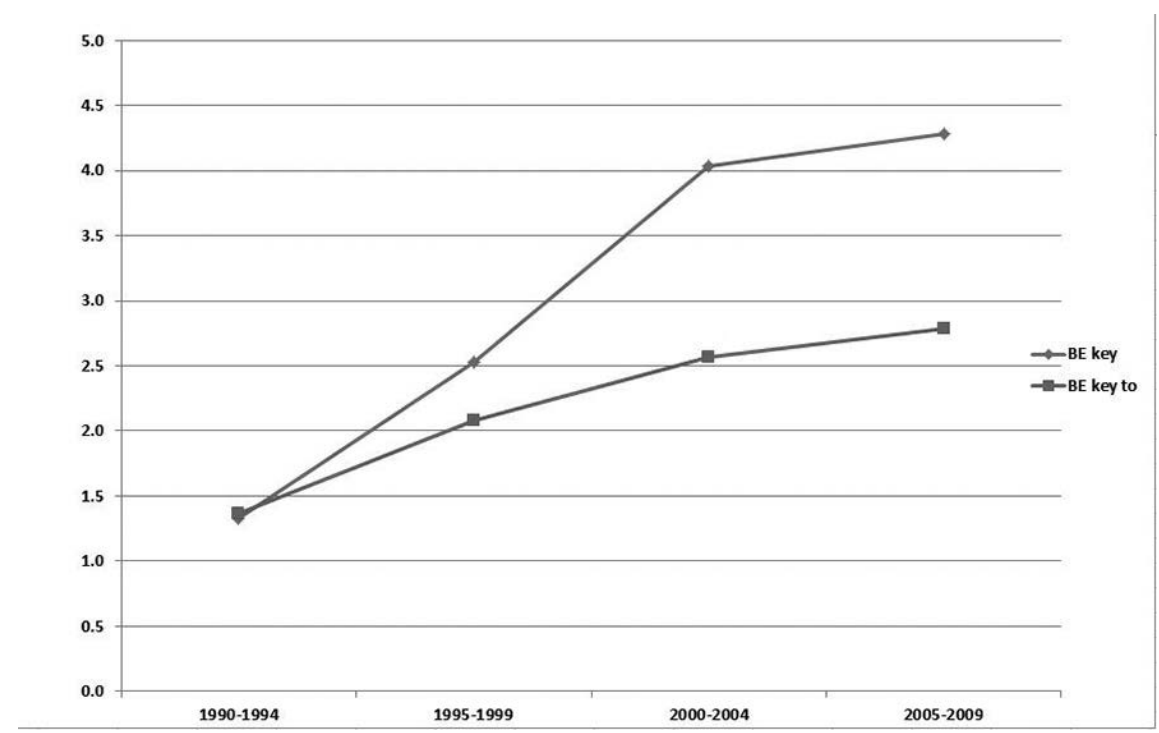

Figure 5. The spread of predicative key in COCA (from data behind De Smet 2012: Fig. 10).

Given that speakers are used to the noun key followed by a to-phrase, they more readily use or accept the new adjectival use of key in a similar context.

I notice that adjectival core is also followed by a to-phrase in 22/31 of COCA examples after the verb $b e,{ }^{17}$ as it is in my own three examples of adjectival use, (32)-(33).

\section{Playing out}

We tend to make the assumption that language users are automata, in that their choices are conditioned by the dictates of their internal grammar and (for sociolinguists) by the statistical probability matching of variation, with perhaps some allowance for expressiveness. Most ordinary speakers live in a sort of synchronic bubble, blissfully unaware of language history. Or so it is assumed, explicitly or implicitly. But in fact some speakers at least are quite aware of change. There are those who discuss it, often to lament or complain about deviations from a real or supposed earlier state, and there are those whose usage suggests that they know they are pushing the boundaries of what is possible. How significant is conscious or semi-conscious language play?

\footnotetext{
${ }^{17}$ Search strings [VB?] core, [VB?] [R*] core. <7 May 2013>. All, needless to say, are tagged as N.
} 


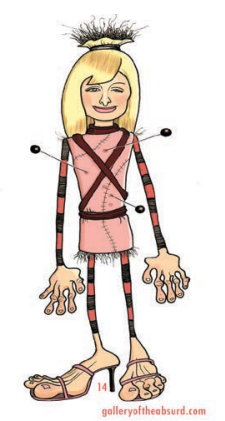

Figure 6. Paris Hilton voodoo doll. (Illustration by galleryoftheabsurd.com.)

Figure 6 displays a Paris Hilton voodoo doll, from a blog called Gallery of the Absurd.$^{18}$ Various commenters praise it as 'hilarious', 'evil', 'fabamundo', and so on, including the comment

(57) its [sic] pure genius 14

(' 14 ' is the sobriquet of the satirical artist.) And soon afterwards a very literate American posts a comment that begins:

(58) Geniuser than the geniusest of the geniusest, dahlink! (2005 http://www.galleryoftheabsurd.com/2005/11/post.html 21.11.2005 (accessed 3 Nov. 2009))

Everything about that line suggests to me that the writer is archly playing with language, pushing the adjectival use of genius in (57) further towards the linguistically risqué.

Another example of knowingly extreme use, from a site for 'connoisseurs of Middlesbrough Football Club', is (59). (The exchange rather declines in rhetorical power: neither of the combatants is exactly Christopher Hitchens.)

(59) B: you are all rubbish and i hate you all

SM: No you are rubbish.

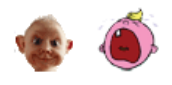

B: you are rubbisher

SM: you are the rubbishest person on this board.

B: rubbish. you are the rubby rubbiesht rubbish person on this board

SM: You are the most rubbishiestest person in the world and stop sending me abusive e-mails about helicopters.

B: you are rubbish at everything, and like rubbish helicopters and rubbish war films (2008, http://forum.comeonboro.com/index.php?topic=24520.0;prev_ next=next (15 Apr.) (accessed 12 Jul 2008))

\footnotetext{
${ }^{18}$ 'It was designed not to cause bodily harm to Paris ... no, each prick of the pin will only embroil her in more scandal and humiliation. We'll be entertained by her downfall, and she'll gain the notoriety she seeks. Everyone wins. Buy one today!' (http://www.galleryoftheabsurd.com/2005/11/post.html).
} 
These extreme examples remind us that simply counting internet or corpus examples willy-nilly runs the risk of calling things grammatical that even their own writers might have felt to be marked or abnormal.

There are other, well-known dangers with internet data, such as the nearimpossibility of normalising frequencies (since the total wordage of the internet is not only unknown but constantly changing), the difficulty of knowing whether you're dealing with native speakers, whether something odd is a simple mistake and therefore whether one is observing the possible start of a change or just an error. The last problem requires hindsight for its solution. As for discriminating between error and change, see Manning (2003) on how the apparent typo as least as (for standard at least as) turned out to be a variant that was spreading just like any other innovation. The responsible thing would be to test claims with speakers, as I have done briefly for rubbish as Adj. Planned future work (Denison in prep., 2015, Felser in prep., 2015) may lead to better evidence.

\section{Living in a prefab}

Everything so far assumes that sentences are made up of words, or of constituents that are themselves made up of words. However, the very concept of word is not entirely straightforward. I'm not too worried about spelling (wind farm vs. wind-farm vs. windfarm), since syntactic definitions of the word rely instead on such properties as whether or not the elements inside it can be moved around or interrupted or picked up by anaphora:

(60) a. ?*It's a wind farm, not a dairy one.

b. It's an *easterly wind farm. [in sense that the installation uses easterly winds]

c. *That farm is wind.

My problem is different. Much of our everyday language is made of prefabricated chunks which occur with higher-than-chance frequency in corpora, may be stored as units in memory, and so on. One set of such prefabs I have been studying for a long time is sort of, kind of and type of. Compare these uses from the British National Corpus:

(61) the Canadians had one sort of sovereign, and the British had another sort

(62) I thought of the place as an imaginary island, a sort of French Never Never Land.

(63) but she should keep those sort of remarks to herself

(64) I hate it when people cry, cos it makes me want to do the same thing. I sort of get this lump in my throat and then my eyes start to sting. 
(65) 'Are you still there?' 'Sort of.'

In (61) it's straightforward to label sort as a noun and of as a preposition. It's less happy in (62), though the meaning and structure are quite different, or in (63), where those agrees for number with remarks rather than sort, and it's hopeless for (64) and (65): it would tell you nothing about the structure or meaning of those sentences to label sort a noun or of a preposition, nor would it capture any useful generalisations. The history of sort of, kind of and type of shows a gradual development over generations of these varied uses, and in most cases there are intermediate stages between two uses where it would be arbitrary to assign an example to one or the other.

Prefabs of varying degrees of unification and varying degrees of compositionality play an enormous part in real language, and a proportion of them should give us pause as to whether it is appropriate to assign a PoS to the constituent words or not.

\section{PART 4: GRAMMAR IN SCHOOLS}

It's all very well pointing out vagueness, variation and difficulty, but in a school context, what is usually expected of a subject like this is clear guidance on Right and Wrong. Teachers, pupils and ministers of state are presumably united on that point.

I mentioned the Glossary of Terms for National Curriculum Assessments (http:// media.education.gov.uk/assets/files/pdf/g/2013\%20ks2_egps_glossaryofterms.pdf), apparently superseded by a glossary that is part of The national curriculum in England: Framework document (July 2013) and clearly influenced by the LAGB glossary of grammatical terminology for schools being drawn up by Dick Hudson and colleagues. The latter aims to offer a set of terms to be used at any primary or secondary level and (ideally) in both English and modern foreign language contexts. The definitions are sensible, reasonably nuanced, and designed where possible to need refinement rather than outright replacement as students move to a higher level or indeed beyond secondary education. The last version of the LAGB glossary that I saw (October 2013) defined noun like this:

noun. E.g. cat, person, arrival, purpose. Nouns - the largest word-class of all-are sometimes called 'naming words' because they name (more technically, refer to) people, places and things. This may be a useful way to remember what nouns are, but doesn't always help to distinguish nouns from other word classes because these can also have similar meanings to nouns; for instance, people can be referred to by pronouns (him, someone), and places by prepositions (behind the sofa).

The most reliable way to recognise nouns is by their grammatical behaviour. Specifically, most nouns: 
- can be counted and show that they're plural if the number is two or more (e.g. one dog, two dog-s, one mouse, two mice),

- can be combined immediately with the (e.g. the dog, the mouse),

- can be used - either alone or with a determiner such as the - as the subject or object of a verb (e.g. The dog was hungry, Mice love cheese.)

Nouns are subdivided into:

- common nouns: dog, wine, time, day, teacher

- proper nouns ('names' in the more conventional sense): Mary, London, Wednesday, Dad

(See also count noun.)

I'm happy with this as a working definition not overburdened by detail. It subtly incorporates the idea of prototype membership via the use of wording like 'doesn't always help', 'the most reliable way', 'most nouns ...'.

Does what I've discussed in this paper have any consequences for grammar in schools? It would be a shame for PoS identification to enter English and Welsh school life again unless it's part of an enjoyable investigation of how language works - and PoS are of course about patterning. However, from 2013 PoS identification is being tested. That's all right in principle, in the way that multiplication tables can be a basis for understanding magnitude and checking calculations, though drilling pupils mechanically to pass the test won't do much good (and could do a lot of harm).

Can pupils and teachers cope with such notions as these?

- A minority of words in real-life discourse are underdetermined for PoS.

- Some common words (e.g. the infinitive marker to) are so idiosyncratic that they don't really pattern much like anything else - calling to a non-finite auxiliary verb is nifty linguistics but counter-intuitive at school level.

- Studying language should be an evidence-based activity.

- Words change, and different speakers have different varieties of English which may involve innovative or obsolescent grammatical behaviour-e.g. a new first-person pronoun in Multicultural London English (Kerswill et al. 2013: 272):

(66) I don’t care what my girl looks like, it's her personality man's looking at I don't know. I hope so. But they will need help.

\section{Out with the old}

I have concentrated on innovations. At a slower rate, old words and old uses die out, which is why pupils need linguistic help with Chaucer, with Shakespeare and even (though much less) with Jane Austen. What about (67) (and see Figure 7)? 


\section{Every littre helps}

Figure 7. Tesco logo. (C Tesco Stores Limited.)

(67) Every little helps.

This saying dates back to the 18th century or earlier. As a slogan to sell groceries, its sell-by date has been extended, but it is rather isolated. Traditional dictionaries call little an adjective. The $O E D$ agrees but says that here, little is a noun. The Cambridge Grammar, on the other hand, says that little is sometimes an adjective, often a determinative (Huddleston \& Pullum 2002: 393-4, 539-40 et passim). John Payne's analysis for every little in (67) in Cambridge Grammar terms is (68) (pers. comm., cf. Payne \& Huddleston 2002: 412), which for just two words is rather complex:

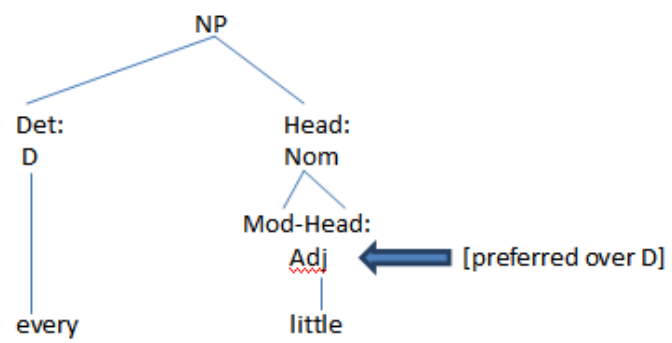

Even then, little could in principle be Adj or D. In the light of Tine Breban's observations on the semantics and distribution, Payne prefers Adj. Observe that every little occurs as an NP only in this fossilised expression. You can't say

(69) *I want every little.

Recent governments have been keen on private enterprise and outsourcing. Would they want this slogan to appear in a multiple-choice school grammar test? What a nightmare question! But with well-motivated, advanced students, what a great example to discuss in class. And more generally: though much of the language we use is explicable by productive rules, some is innovative and bends those rules, and some is fossilised and not wholly amenable to explanation by present-day rules.

\section{PART 5: CONCLUSIONS}

Parts of speech: are they solid citizens or slippery customers? Fairly solid, I would say, if we treat them as morphosyntactic generalisations about the vocabulary of English, only imperfectly correlated with semantics. 
With admirable clarity of purpose, the Cambridge Grammar always tries to figure out the best analysis when there is a choice. The trouble with this is two-fold. By rejecting the less good analysis, but one which nevertheless was persuasive enough to require detailed rejection, it doesn't allow for the part played in a speaker's grammar by the analogies of that second analysis. And historically, by rejecting reanalysis until all evidence of the older state has disappeared entirely, it has no explanation for gradually changing distributions and dispositions over time.

Often change comes first in semantics, and then morphosyntax is bent to catch up. Van Goethem \& De Smet (in press: §2) show how the noun average changed its meaning before starting to show adjectival properties; cf. also Vartiainen (2013). Similarly, powerhouse changed meaning before becoming an adjective, see the section Gradual change above. Notional definitions do therefore have some role in $\mathrm{PoS}$ even within a single language.

PoS represent abstract generalisations about the behaviour of (in the case of N, Adj, V) thousands and thousands of words. Reynolds \& Pullum (in prep.) have established that there cannot be a rigid distinction between open classes like N, Adj, V, which accept new items freely, and so-called closed classes like Particle and Pronoun, which have a smaller, fixed inventory; rather, some classes are opener and some closeder. The best we can aim for is a hierarchy of openness. The membership of all classes changes. New items arrive (new words, new uses of existing words), and old ones die out. So we have a slowly changing and very large set of words. They take part in a complex web of syntactic patterns and convey one or many senses. Neither syntax nor semantics is fixed. So the PoS inevitably change too. And the smaller the class, potentially the more radical the change, because a PoS is essentially an average behaviour of its members. If a class is already large, a few new members won't change the average much. Nevertheless, even the major, open classes N, Adj and V, cannot be defined in the same way over the whole historical span of English. And two minor classes, Modal verb and Determiner, have only arrived in English grammar during the historical period, and both are changing rapidly at the moment.

Like all good grammatical systems I have encountered, PoS make useful generalisations. Like all systems I've encountered so far, there's a residue which doesn't fit neatly - the bubble under the sticky plastic that you can't smooth out. Language resists being smoothed out and displayed as a neatly labelled specimen. It's a living thing (mixed metaphors and all!). That's why it's such/so fun. 


\section{CORPORA CITED}

19CAmNews $=19$ th Century U.S. Newspapers. Gale Databases.

ANC2 $=2009$. American National Corpus, 2nd edition. Linguistic Data Consortium.

$\mathrm{BNC}=2007$. The British National Corpus, version 3 (BNC XML Edition). Oxford University Computing Services on behalf of the BNC Consortium.

CLMET 3.0 = De Smet, Hendrik, Hans-Jürgen Diller \& Jukka Tyrkkö. 2013. Corpus of Late Modern English Texts.

COCA = Davies, Mark. 2008-. The Corpus of Contemporary American English: 450 million words, 1990-present. Available online at http://corpus.byu.edu/coca/. Brigham Young University.

COHA $=$ Davies, Mark. 2010. The Corpus of Historical American English: 400 million words, 18102009. Available online at http://corpus.byu.edu/coha/. Brigham Young University.

HC = Rissanen, Matti \& Merja Kytö. 1984-1991. Helsinki Corpus of English Texts. University of Helsinki.

TMC $=$ Davies, Mark. 2007-. TIME Magazine Corpus: 100 million words, 1920s-2000s. Available online at http://corpus.byu.edu/time/. Brigham Young University.

WebCorp =WebCorp: Linguist's search engine. Birmingham City University. Available online at http://www.webcorp.org.uk/.

\section{REFERENCES}

Aarts, B. (2007), Syntactic gradience: the nature of grammatical indeterminacy (Oxford, Oxford University Press).

Algeo, J. (1962), 'A fun thing', American Speech, 37.2: 158-9. http://dx.doi.org/10.2307/453156

Anderson, J.M. (1997), A notional theory of syntactic categories (Cambridge Studies in Linguistics 82; Cambridge, Cambridge University Press).

Bauer, L. (2003), “"ou tout se tient”", LINGUIST LIST, 14: 1954. http://linguistlist.org/issues/14/141954.html (accessed 12 Jan. 2013).

Bolinger, D. (1976), 'Meaning and memory', Forum Linguisticum, 1: 1-14.

Bolinger, D.L. (1963), 'It's so fun', American Speech, 38.3: 236-40.

Breban, T. (2008), 'Grammaticalization, subjectification and leftward movement of English adjectives of difference in the noun phrase', Folia Linguistica, 42.2: 259-306.

Bybee, J. \& Beckner, C. (submitted), 'Language use, cognitive processes and linguistic change', in C. Bowern \& B. Evans (eds), Routledge handbook of historical linguistics (London, Routledge).

Bybee, J. \& Cacoullos Torres, R. (2009), 'The role of prefabs in grammaticization: how the particular and the general interact in language change', in R. Corrigan, E.A. Moravcsik, H. Ouali \& K.M. Wheatley (eds), Formulaic language, 2 vols, vol. 1, Distribution and historical change (Typological Studies in Language 82; Amsterdam, John Benjamins), 187-218.

Croft, W. (2000), Explaining language change: an evolutionary approach (Longman Linguistics Library; Harlow, Longman).

Croft, W. (2001), Radical Construction Grammar: syntactic theory in typological perspective (Oxford, Oxford University Press). http://dx.doi.org/10.1093/acprof:oso/9780198299554.001.0001

Croft, W. (2005a), 'Logical and typological arguments for Radical Construction Grammar', in J.-O. Östman \& M. Fried (eds), Construction grammars: cognitive grounding and theoretical extensions (Constructional Approaches to Language 3; Amsterdam \& Philadelphia, John Benjamins), 273-314. 
Croft, W. (2005b), 'Word classes, parts of speech, and syntactic argumentation', Linguistic Typology, 9.3: 431-41.

De Smet, H. (2012), ‘The course of actualization', Language, 88.3: 601-33. http://dx.doi.org/10.1353/lan.2012.0056

Denison, D. (1986), 'On word order in Old English', Dutch Quarterly Review, 16: 277-95.

Denison, D. (2001), 'Gradience and linguistic change', in Laurel J. Brinton (ed.), Historical linguistics 1999: selected papers from the 14th International Conference on Historical Linguistics, Vancouver, 9-13 August 1999 (Current Issues in Linguistic Theory, 215; Amsterdam \& Philadelphia, PA, John Benjamins), 119-44.

Denison, D. (2003), 'Log(ist)ic and simplistic S-curves', in Raymond Hickey (ed.), Motives for language change (Cambridge, Cambridge University Press), 54-70.

Denison, D. (2010), 'Category change in English with and without structural change', in E. Closs Traugott \& G. Trousdale (eds), Gradience, gradualness and grammaticalization (Typological Studies in Language 90; Amsterdam \& Philadelphia, John Benjamins), 105-28.

Denison, D. (in prep.), English word classes: categories and their limits (Cambridge Studies in Linguistics; Cambridge, Cambridge University Press).

Denison, D. (in prep., 2015), 'Ambiguity and vagueness in historical change', in M. Hundt, S. Mollin \& S. Pfenninger (eds), The changing English language: psycholinguistic perspectives (Studies in English Language; Cambridge, Cambridge University Press).

Deutscher, G. (2005), The unfolding of language (London, William Heinemann).

Emonds, J. (1972), 'Evidence that Indirect Object Movement is a structure-preserving rule', Foundations of Language, 8: 546-61.

Feist, J. (2012), Premodifiers in English: their structure and significance (Studies in English Language; Cambridge, Cambridge University Press).

Felser, C. (in prep., 2015), 'Syntactic ambiguity in real-time language processing and diachronic change', in M. Hundt, S. Mollin \& S. Pfenninger (eds), The changing English language: psycholinguistic perspectives (Studies in English Language; Cambridge, Cambridge University Press).

Giegerich, H.J. (2012), 'The morphology of -ly and the categorial status of 'adverbs' in English', English Language and Linguistics, 16.3: 341-59. http://dx.doi.org/10.1017/S1360674312000147

Goldberg, A.E. (2006), Constructions at work: the nature of generalization in language (Oxford, Oxford University Press).

Harris, A.C. \& Campbell, L. (1995), Historical syntax in cross-linguistic perspective (Cambridge Studies in Linguistics 74; Cambridge, Cambridge University Press).

Haspelmath, M. (1998), 'Does grammaticalization need reanalysis?', Studies in Language, 22.2: 315-51. http://dx.doi.org/10.1075/s1.22.2.03has

Hewson, J. (1990), 'Un système où tout se tient: origin and evolution of an idea', in H.-J. Niederehe \& E.F.K. Koerner (eds), History and historiography of linguistics: proceedings of the fourth International Conference on the History of the Language Sciences (ICHoLS IV), Trier, 24-28 August 1987, 2 vols (Studies in the History of the Language Sciences 51; Amsterdam, John Benjamins), vol. 2, 787-94.

Huddleston, R. (1984), Introduction to the grammar of English (Cambridge Textbooks in Linguistics; Cambridge, Cambridge University Press).

Huddleston, R. \& Pullum, G.K. (2002), The Cambridge grammar of the English language (Cambridge, Cambridge University Press).

Hudson, R. (2000), ‘*I amn't', Language, 76.2: 297-323.

Hudson, R. (2006. Language networks: the new Word Grammar (Oxford \& New York, Oxford University Press).

Hudson, R. (2013), 'A cognitive analysis of John's hat', in K. Börjars, D. Denison \& A. Scott (eds), 
Morphosyntactic categories and the expression of possession (Linguistik Aktuel1/Linguistics Today 199; Amsterdam, John Benjamins), 149-75.

Hudson, R. \& Walmsley, J. (2005), 'The English Patient: English grammar and teaching in the twentieth century', Journal of Linguistics, 41.3: 593-622. http://dx.doi.org/10.1017/S0022226705003464

Hudson, R.A. (1990), English word grammar (Oxford, Basil Blackwell).

Hundt, M. (2013), 'Who is the/a/Ø professor of English at your university?'. Paper presented at ICAME34, Santiago de Compostela.

Jackendoff, R. (1977), X syntax: a study of phrase structure (Linguistic Inquiry monographs 2; Cambridge, MA \& London, MIT Press) [sometimes printed as $X$ syntax or $X$-bar syntax].

Jespersen, O. (1909-49), A Modern English grammar on historical principles, 7 vols. (Heidelberg, Carl Winters Universitätsbuchhandlung; repr. London, George Allen \& Unwin), 1961.

Jespersen, O. (1924), The philosophy of grammar (London, George Allen \& Unwin).

Kerswill, P., Cheshire, J., Fox, S. \& Torgersen, E. (2013), 'English as a contact language: the role of children and adolescents', in D. Schreier \& M. Hundt (eds), English as a contact language (Studies in English Language; Cambridge, Cambridge University Press), 258-82.

Kiparsky, P. (forthcoming), 'New perspectives in historical linguistics', in C. Bowern \& B. Evans (eds.), The Routledge handbook of historical linguistics (Routledge Handbooks in Linguistics; London, Routledge).

Koerner, E. F. K. (2004), 'Three Saussures - one "structuralist” avant la lettre', in E. F. K. Koerner (ed.), Essays in the history of linguistics (Studies in the History of the Language Sciences 104; Amsterdam, John Benjamins), 175-94.

Langacker, R.W. (2008), 'Grammatical classes', Cognitive Grammar: a basic introduction (Oxford, Oxford University Press). http://dx.doi.org/10.1093/acprof:oso/9780195331967.001.0001

Lee, D.W., (1948), Functional change in early English (Menasha, Wisconsin. George Banta Publishing Company).

Manning, C.D. (2003), 'Probabilistic approaches to syntax', in R. Bod, J. Hay \& S. Jannedy (eds), Probabilistic linguistics, 289-341 (Cambridge, MA, MIT Press).

Marchand, H. (1969), The categories and types of Present-Day English word-formation: a synchronic-diachronic approach, 2nd edn (Munich, Beck'sche Verlagsbuchhandlung).

McCawley, J.D. (1982), 'The nonexistence of syntactic categories', Thirty million theories of grammar (London, Croom Helm), 176-203.

Mutt, O. (1964), 'The adjectivization of nouns in English', Zeitschrift für Anglistik und Amerikanistik, 12: $341-9$.

Mutt, O. (1967), 'Some recent developments in the use of nouns as premodifiers in English', Zeitschrift für Anglistik und Amerikanistik, 15: 401-8.

Mutt, O. (1976), 'Some notes on the predicative use of nouns in English', Zeitschrift für Anglistik und Amerikanistik, 24.2: 101-9.

Nesbitt, M.L. (1889), Grammar-Land: or, grammar in fun for the children of Schoolroomshire, 4th edn (London, Houlston \& sons; repr. British Library, 2010).

Payne, J. \& Huddleston R. (2002), 'Nouns and noun phrases' in R. Huddleston \& G.K. Pullum (eds), The Cambridge grammar of the English language (Cambridge, Cambridge University Press), 323-523.

Payne, J., Huddleston R. \& Pullum, G.K. (2010), 'The distribution and category status of adjectives and adverbs', Word Structure, 3: 31-81. http://dx.doi.org/10.3366/E1750124510000486

Pullum, G.K. (2009), 'Lexical categorization in English dictionaries and traditional grammars', Zeitschrift für Anglistik und Amerikanistik, 57.3: 255-73.

Quirk, R., Greenbaum, S., Leech, G. \& Svartvik, J. (1985), A comprehensive grammar of the English language (London \& New York, Longman).

Radford, A. (1988), Transformational grammar: a first course (Cambridge Textbooks in Linguistics; Cambridge, Cambridge University Press). 
Rauh, G. (2010), Syntactic categories: their identification and description in linguistic theories (Oxford Surveys in Syntax and Morphology 7; Oxford and New York, Oxford University Press).

Reynolds, B. \& Pullum, G. K. (in prep.), 'New members of "closed" word classes in English'. http://ling.ed.ac.uk/ gpullum/ClosedClasses.pdf (Accessed 8 Nov. 2013).

Ross, J.R. (1973), 'Nouniness', in O. Fujimura (ed.), Three dimensions of linguistic theory (Tokyo, TEC for Tokyo Institute for Advanced Studies of Language, 137-257; repr. Aarts et al. (eds), Fuzzy Grammar (2004), 351-422.

Van Goethem, K. \& De Smet, H. (in press), 'How nouns turn into adjectives: the emergence of new adjectives in French, English and Dutch through debonding processes', Languages in Contrast.

Vartiainen, T. (2013), 'Subjectivity, indefiniteness and semantic change', English Language and Linguistics, 17.1: 157-79. http://dx.doi.org/10.1017/S1360674312000354

Whorf, B.L. (1956), Language, thought and reality: Selected writings of Benjamin Lee Whorf (Cambridge, MA, MIT Press; repr. electronic edition).

The author: David Denison holds the Smith Chair in English Language at the University of Manchester and has held visiting professorships at universities in Europe and North America. Internationally recognised as a leading expert on the evolution of English grammar, he has published widely on historical and present-day change in grammatical categories and constructions and has advised on the preparation of materials for teaching grammar in schools.

Contact: david.denison@manchester.ac.uk

This article is licensed under a

Creative Commons Attribution-NonCommercial-NoDerivs 3.0 Unported License.

Journal of the British Academy (ISSN 2052-7217) is published by

The British Academy - the national academy for the humanities and social sciences.

10-11 Carlton House Terrace, London, SW1Y 5AH

www.britishacademy.ac.uk 
